\title{
Gendered determinants of food insecurity in ongoing regional conflicts, North and South Kivu, the Democratic Republic of Congo
}

Wyvine Ansima Bapolisi 1,2,3* ${ }^{*}$, Giovanfrancesco Ferrari ${ }^{1}$, Ghislain Bisimwa ${ }^{3}$ and Sonja Merten ${ }^{1,2}$

\begin{abstract}
Background: Food insecurity remains a major concern worldwide. In North and South Kivu provinces, the Democratic Republic of the Congo, repeated wars and gender-based violence exacerbate the situation. However, little is known about the determinants of food insecurity in the region.

Objective: This study analyzed the gendered determinants of food insecurity in North and South Kivu in the Democratic Republic of Congo, a region of ongoing civil conflict.

Methods: 1754 women were included in a cross-sectional study. Multilevel ordinal logistic regression was used to identify household-level determinants of food insecurity.

Results: The poorest households were five times more likely to be food insecure ( $\mathrm{OR}=5.66,95 \% \mathrm{Cl} 3.74-8.55)$. Women's participation in decision-making about resource allocation decreased the risk for household food insecurity $(\mathrm{OR}=0.68,95 \% \mathrm{Cl} 0.57-0.87)$, while higher tolerance to gender-based violence increased the risk of food insecurity $(\mathrm{OR}=1.29,95 \% \mathrm{Cl} 1.05-1.54)$.
\end{abstract}

Conclusion: Involving empowered women in decision-making about resource allocation and actions to reduce gender-based violence could help mitigate food insecurity.

Keywords: Household food insecurity, Gender-based violence, Decision-making, Wealth perception, Kivu

\section{Background}

Worldwide, food insecurity is a major concern: over 820 million people are estimated to suffer from hunger which translates to one in nine persons globally [1]. Food insecurity is a social as well as a biological, nutritional, and economic phenomenon [2]. Food security is achieved when all people in the household, at all times, have physical, social, and economic access to sufficient, safe, and nutritious food which meets their dietary needs and food preferences for an active and healthy life [3]. Food security is about availability, stability, accessibility, and utilization: food availability is necessary but not sufficient for

\footnotetext{
*Correspondence: wyvine.bapolisi@swisstph.ch

1 swiss Tropical and Public Health Institute, Basel, Switzerland

Full list of author information is available at the end of the article
}

access, access is necessary but not sufficient for utilization, and stability is necessary but not sufficient for utilization [4].

For years, blanket strategies were implemented to achieve food security across entire world regions. Evidence demonstrates, however, that every region faces unique challenges and solutions should therefore be adapted to context [5-8]. Authors examining determinants of food insecurity found that household gender dynamics are key. In several studies, households headed by men were more likely to have a low level of food insecurity [9-12]. However, some authors postulate that differences in food insecurity lie not so much in the gender of the household head but some unobserved differences affecting the use of household resources [13]; others point to the lack of women decision-makers in 
the household [14, 15]. Some authors working in African contexts advocate that female heads of households will enhance household food security as women are in charge of food preparation, processing, and preservation [16, 17]. Few authors have studied other aspects of the gender power balance in decision-making, including genderbased violence and its impact on food insecurity.

One in four people in Africa faces widespread and chronic malnutrition as well as a constant threat of acute food crisis and famine $[8,18,19]$. The Democratic Republic of Congo (DRC) is one sub-Saharan country where food insecurity persists. The DRC ranks among the poorest countries in the world [20]. In 2018, approximately 13.1 million Congolese experienced acute food insecurity and livelihood crisis with $51 \%$ of the population farming [21-23]. The combination of persistent armed conflict, massive population displacement, poor or non-existent infrastructure, and widespread deterioration of productive assets has significantly affected food security in the DRC. With growing insecurity in rural areas due to civil wars, land is abandoned leading to urban overpopulation. Kasai, South Kivu, North Kivu, Ituri, Maniema, and Tanganyika provinces are facing population displacement which limits households' abilities to access typical livelihood activities and places many at risk for food insecurity [22, 24]. Simultaneously, gender-based violence is increasing in the Kivu region [25-29]. South Kivu has one of the high burdens of sexual violence in the country. According to the Demographic Health Survey (DHS), $34.5 \%$ of women were victims of sexual violence in 2014 [23].

Few studies investigating the gendered dimensions of food insecurity in ongoing conflict zones in DRC exist. The purpose of this study is to explore the determinants of household food insecurity in North and South Kivu, DRC, including decision-making and head of household gender. This analysis will help inform specific actions to be taken to address food insecurity in these and similar regions.

\section{Method}

\section{Study setting}

Data were collected as part of an evaluation of a gender empowerment project in North and South Kivu, DRC from March to December 2017. Data were collected in both rural (Walungu, South Kivu and Rusthuru, North Kivu) and urban (Goma and Karisimbi in North Kivu, and Ibanda, Bagira, and Kadutu in South Kivu) contexts.

\section{Study design and sampling}

This paper analyzes cross-sectional data from women who participated in the baseline study of the "Mawe tatu" project aimed at improving household socio-economic status through village saving and loan associations (VSLA) approach. The project Mawe tatu targeted persons of "lower" socio-economic background and selected women for participation by using community-based targeting--approaching community leaders to provide listings with vulnerable households and invite women from these households to an initial meeting--but participation in the project was voluntary. To select villages to be included in this study, cluster randomized sampling was used. The power calculation was based on the hypothesis that village saving and loan systems lower the risk of stunting in children. The sample size calculation has been described in detail elsewhere [30]. 80 villages were randomly selected for inclusion in this study, and in each village, participants were randomly selected from new VLSLAs implemented by the Mawe tatu project.

23,000 women were expected to take part in the Mawe tatu project of whom a minimum of 1200 women were to be included in the baseline study. For villages with one new VSLA, 15 women were recruited for this study. For villages with two or more new VSLAs, 25 women were recruited. Ultimately, 1754 women were enrolled in this study.

\section{Instruments}

The questionnaire included questions about household food insecurity and socio-economic variables that affect food insecurity including age, sex, gender, education level, household size, employment status, and self-rated level of household poverty compared to the surrounding community. To ensure unbiased answers on the self-rated level of household poverty, a previously validated scale was used [31]. In addition, research assistants ranked households' wealth based on the construction of the house (mud house, mud house with an iron sheet roof, brick house). Further questions included the relation of the participants to the household head, the main breadwinner, the main household decision-maker, and attitudes toward gender-based violence and gender inequality. Scales were used to measure respondent food insecurity, attitudes toward gender-based violence, and intra-household decision-making.

\section{Food insecurity measurement}

Food insecurity was the main outcome of interest. Food insecurity was defined by the globally employed Food and Agriculture Organization's Food Insecurity Experience Scale (FIES) [3], used in previous studies on food insecurity [32, 33]. Since the dependent variable was food insecurity, the FIES was computed as a summativescaled score with ten items (yes/no responses), categorizing household food insecurity into three levels: severe, 
moderate, and mild. The recall time question was of four weeks (or 30 days).

\begin{tabular}{|c|c|c|c|}
\hline \multirow{2}{*}{$\begin{array}{l}\text { Mild food } \\
\text { insecurity }\end{array}$} & \multicolumn{2}{|c|}{ Moderate food insecurity } & \multirow{2}{*}{$\begin{array}{c}\begin{array}{l}\text { Severe food } \\
\text { insecurity }\end{array} \\
\begin{array}{c}\text { Experiencing } \\
\text { hunger }\end{array} \\
\end{array}$} \\
\hline & $\begin{array}{l}\text { Compromising } \\
\text { quality and } \\
\text { variety of food }\end{array}$ & $\begin{array}{l}\text { Reducing quan- } \\
\text { tities, skipping } \\
\text { meals }\end{array}$ & \\
\hline
\end{tabular}

Many authors have studied food insecurity as an ordinal categorical variable [13,34, 35]. Due to the high prevalence of food insecurity in the study region, a summative scale was computed to assess the difference in the households according to their experience. To ensure that the model was not sensitive to outliers (robustness), percentiles were created from the FIES scale.

\section{Decision-making and gender-based violence measurements}

The items included in intra-household, summative scales measuring decision-making and tolerance of genderbased violence (GBV) were defined according to previous studies, including DHS $[23,36]$.

Items included the following: "Who in your household usually decides on special expenditures such as health care?" "More specifically, who decides where to seek care for maternal and child health issues?" "Who in your household usually decides if you personally want to take a loan?" "Who in your household decides if someone in your household wants to buy or sell a mobile phone?" "Who in your household decides regarding buying or selling land?" "Who in your household decides how your own income is used?" "Who in your couple decides when to have children?" "Who in your couple decides whether to use family planning?" Each item was coded 1 if the woman was participating in the household decision-making and 0 if not, then the summative scale was computed.

For the tolerance of GBV scale, nine binary items were retained based on previous studies in the region $[23,36]$ : (a)"It is normal that a man beats his wife if she is unfaithful"; (b) "It is normal if a parent beats a girl if she is getting pregnant outside of marriage"; (c) "It is normal if a man beats his wife if she doesn't want to have sex with him"; (d) "If someone insults a man he must defend his reputation using violence if needed"; (e) "If a person wastes money it is normal that he/she is beaten"; (f) "It is normal that a man beats his wife if she goes out without telling him"; (g)"It is normal that a man beats his wife if she argues with him"; (h) "It is normal that a man beats his wife if she neglects the children"; and (i)" It is normal that a man beats his wife if she burns the food". Then, a summative scale was computed for each participant.

\section{Data collection}

Data were collected using tablets with the Open Data Kit software package; questions were translated into the main local language, Swahili. A team of 20 local researchers fluent in locally spoken languages was trained over a week in data collection methods, followed by a pilot study. Regular data quality checks were done using a short verification questionnaire with a randomly selected sub-sample of 30 participants right after the interview and consistent field supervision. Data were stored on a secured server accessed only by core research team members.

\section{Data analysis}

Mokken analysis is a non-parametric procedure based on item response theory and helped confirm the unidimensionality and reliability of the food insecurity, decision, and violence scales. Mokken analysis was used to assess similar scales in previous studies [37, 38]. Mokken scale analysis establishes hierarchies of items. Three basic assumptions are required: unidimensionality, local independence, and monotonicity. Scale homogeneity is based on Loevinger's index of homogeneity $H$ [39]. As a rule of thumb Loevinger's coefficient $H<0.30$ indicates poor scalability properties, for $0.30<H<0.40$ the scale is weak; for $0.40<H<0.50$ the scale is medium, and for $H>0.50$ the scale is strong. The reliability of Mokken scales is estimated using Rho, which is a test-retest reliability coefficient with Rho $>0.7$ considered to indicate a reliable scale [40]. The items that satisfied the three assumptions of the Mokken analysis can be added up and individual scores are then computed as the rank of the highest endorsed item in this hierarchy, i.e., it is a simple total score (sum of positive responses). This total score is used as an estimate of the level of the latent construct, in this case, decision-making, violence scale, and food insecurity in each subject.

Intra-household decision-making: All items were included in the scale using (msp average inter-item correlation: 0.46 ; scale reliability coefficient 0.88 ; $\mathrm{Hjk} 0.839$ ).

Tolerance of gender-based violence scale: Ten items were included in the retained scale, score of reliability 0.74; average inter-item correlation 0.227; Hjk 0.776).

Bivariate binary logistic regression analysis was performed to show the crude association between food insecurity (the outcome) and the exposure variables of interest (age, education, marital status, relation to the head of the family, number of children, wealth perception, breadwinner, decision-making in the couple, and violence scale). Then a multilevel ordinal regression was used to identify determinants of household food insecurity by using the adjusted association between food 
insecurity and the exposure variables. In post-conflict zones, multilevel ordinal regression has been established as a robust method to study the determinants of food insecurity [34]. Mixed-effects models were used to account for the clustering design. The Hosmer-Lemeshow goodness-of-fit was used to check if the necessary assumptions for multilevel logistic regression were fulfilled. The model had a $p$-value $>0.05$, suggesting that the model fit the data well. The AIC was used to compare different models; the model with the lowest AIC was retained. Odds ratios with $95 \%$ confidence intervals (CI) were calculated and the statistical significance was accepted at the $5 \%$ level of significance $(p<5 \%)$. Data were analyzed using Stata 15.0.

\section{Ethical issues}

Informed verbal and written consent was obtained from each individual before the beginning of data collection and all consent forms were translated into local languages.

Participation in this study was voluntary, and refusal to participate in the study had no repercussion whatsoever. Confidentiality was guaranteed. Any participant requesting help or information on a particular topic including GBV was referred to the closest health care facility. No fees were required of participants and no compensation was offered in exchange for participation in this study.

\section{Results}

\section{Respondent and respondent household} socio-demographics

1754 households were included in this study. Table 1 summarizes the socio-demographic characteristics of the households.

The mean age of the study population was $36 \pm 12$ years. The majority of the study population $53.9 \%(n=946)$ was aged between 20 and 39 years. $42.6 \%(n=745)$ of the sample reached the secondary level at school, $76.1 \%$ $(n=1333)$ were married, and $70.4 \%(n=1237)$ were living in urban areas. More than half $54.3 \%(n=953)$ of the sample size reported they were self-employed, mostly involved in small business. $70.5 \%(n=1237)$ of the participants lived in urban settings. The mean average of the household size was $7.5 \pm 3.1$ people. The mean meals per day was $1.8 \pm 0.6$ meals. $42.5 \%(n=666)$ of people interviewed perceived their household to have the same wealth as the neighborhood and more than $31 \%(n=486)$ estimated that they considered themselves somewhat poorer than others (Table 1). More than $70 \%(n=1190)$ reported their husband or partner as the head of the household (Table 1). Most households reported having a male breadwinner.

\section{Food insecurity}

Table 2 reports household FIES with a recall period of four weeks (30 days).

$71.0 \%(n=1243)$ went without eating for a whole day because of lack of money and other resources and 78.3\% $(n=1339)$ participants reported that children were not given enough food to eat (Table 2). Classifying the households' food insecurity according to FIES, almost all of the study population was experiencing food insecurity, with $87.8 \%$ of the respondents experiencing severe food insecurity and only $5.5 \%$ reporting to have been food secure (Table 3).

Table 4 presents household food insecurity classes using percentiles.

The multilevel ordinal logistic regression assessed risk factors for food insecurity levels generated from the 10 quantiles of the summative scale. Odds ratios associated with food insecurity are presented in Table 5 .

Participants perceiving their household as "poorer" or "much poorer" were, respectively, three times and five times more likely to be food insecure ( $\mathrm{OR}=3.31,95 \%$ CI 2.50-4.38; OR $=5.66,95 \%$ CI3.74-8.55, respectively). The more the woman was participating in decision-making, the less likely the household was to be food insecure $(\mathrm{OR}=0.68,95 \% \mathrm{CI} 0.53-0.87)$. Higher tolerance of gender-based violence increased the risk of the household being food insecure (OR $=1.29$, 95\% CI 1.05-1.59). Women who were employed or self-employed were more likely to be food insecure (respectively, OR $=1.56,95 \%$ CI 1.17-2.07 and OR=2.26, 95\% CI 1.48-3.45). Having a secondary level of education decreased the risk of the household being food insecure ( $\mathrm{OR}=0.59,95 \% \mathrm{CI} 0.40$ 0.87 ). Perceiving oneself "somewhat richer" than others and living in an urban area decreased the risk of the household being food insecure (OR $=0.35$, 95\% CI 0.24 0.52 ; $\mathrm{OR}=0.48$, 95\% CI0.32-0.71, respectively). Households headed by the husband or male partner were less likely to be food insecure ( $\mathrm{OR}=0.56,95 \% \mathrm{CI} 0.35-0.90)$, but the association was not statistically significant.

\section{Discussion}

Socio-demographic characteristics of the studied sample were consistent with regional socio-demographics reported in the most recent DHS survey, giving the sample credibility to be representative of the community.

The observed difference between being the head of the family and being the breadwinner is of note but has been described as the result of the high unemployment rate and the development of small activities by women to ensure the survival of the family $[41,42]$.

The study results indicated that food insecurity is very high in eastern DRC, which correlates with reports from 
Table 1 Socio-demographics characteristics of respondents

\begin{tabular}{|c|c|c|}
\hline Variables & Frequency & Percentage \\
\hline Age (mean) & $n=1754$ (36 years \pm 12.9 years $)$ & \\
\hline Less than 20 years old & 98 & 5.6 \\
\hline $20-29$ & 472 & 26.9 \\
\hline $30-39$ & 474 & 27.0 \\
\hline $40-49$ & 428 & 24.4 \\
\hline$\geq 50$ & 282 & 16.1 \\
\hline Education & $n=1748$ & \\
\hline None & 336 & 19.2 \\
\hline Primary & 575 & 32.9 \\
\hline Secondary & 745 & 42.6 \\
\hline University & 92 & 5.3 \\
\hline Married & $n=1752$ & \\
\hline No & 419 & 23.9 \\
\hline Yes & 1333 & 76.1 \\
\hline Residence & $n=1754$ & \\
\hline Urban & 1237 & 70.5 \\
\hline Rural & 517 & 29.4 \\
\hline Occupation (main occupation of the household) & $n=1754$ & \\
\hline Employment (any) & 382 & 21.8 \\
\hline Self-employment & 953 & 54.3 \\
\hline No employment & 419 & 23.9 \\
\hline Household size & $n=1754$ (7.5 \pm 3.12 people $)$ & \\
\hline$\leq 4$ & 287 & 16.4 \\
\hline $5-7$ & 613 & 35.0 \\
\hline $8-10$ & 599 & 34.1 \\
\hline More than 10 & 255 & 14.5 \\
\hline Land & $n=1748$ & \\
\hline Yes & 1029 & 59 \\
\hline No & 719 & 41 \\
\hline Number of meal per day & $n=1754(1.82 \pm 0.61$ meals $)$ & \\
\hline Wealth perception & $n=1565$ & \\
\hline Much richer than others & 11 & 0.7 \\
\hline Somewhat richer than other & 126 & 8.0 \\
\hline The same & 666 & 42.5 \\
\hline Somewhat poorer than other & 486 & 31.0 \\
\hline Much poorer than others & 276 & 17.6 \\
\hline Relation to the head of the household & $n=1686$ & \\
\hline Respondent is the head & 361 & 21.4 \\
\hline Partner is the household head & 1190 & 70.6 \\
\hline Respondent's relative is the head & 110 & 6.5 \\
\hline Partner's relative is the head & 25 & 1.5 \\
\hline Breadwinner in the household & $n=1727$ & \\
\hline Male & 974 & 56.4 \\
\hline Female & 500 & 28.9 \\
\hline Relative & 253 & 14.7 \\
\hline
\end{tabular}


Table 2 Food insecurity (FIES)

\begin{tabular}{|c|c|c|c|}
\hline Food insecurity & Frequency & Percentage & $\begin{array}{l}\text { Level } \\
\text { of food } \\
\text { insecurity }\end{array}$ \\
\hline You were worried you would run out of food because of a lack of money or other resources & 1446 & 82.8 & Mild \\
\hline You were unable to eat healthy and nutritious food because of a lack of money or other resources & 1459 & 83.6 & Moderate \\
\hline You ate only a few kinds of foods because of a lack of money or other resources & 1379 & 79.0 & Moderate \\
\hline You had to skip a meal because there was not enough money or other resources to get food & 1444 & 82.7 & Moderate \\
\hline You ate less than you thought you should because of a lack of money or other resources & 1455 & 83.2 & Moderate \\
\hline Your household ran out of food because of a lack of money or other resources & 1472 & 84.4 & Severe \\
\hline You were hungry but did not eat because there was not enough money or other resources for food? & 1308 & 74.9 & Severe \\
\hline You went without eating for a whole day because of a lack of money or other resources & 1243 & 71.0 & Severe \\
\hline Your children were not able to eat healthy or nutritious foods & 1330 & 78.0 & Moderate \\
\hline Your children were not given enough food to eat because of a lack of money or other resources & 1339 & 78.3 & Moderate \\
\hline
\end{tabular}

Table 3 Household food insecurity level

\begin{tabular}{lcc}
\hline Level of food insecurity & Frequency $\boldsymbol{n = 1 7 4 2}$ & Percentage \\
\hline Food secure & 96 & 5.5 \\
Mild food insecurity & 7 & 0.4 \\
Moderate food insecurity & 109 & 6.3 \\
Severe food insecurity & 1530 & 87.8 \\
\hline
\end{tabular}

Due to the very high prevalence of food insecurity, we could not run a logistic regression to find the determinants of food insecurity using this scale.

Table 4 Summative scale of household food insecurity

\begin{tabular}{llc}
\hline 10 Quantiles of food scale & $\begin{array}{l}\text { Frequency } \\
\boldsymbol{n = 1 7 5 0}\end{array}$ & Percentage \\
\hline Level 1 & 170 & 9.7 \\
Level 2 & 182 & 10.3 \\
Level 3 & 168 & 9.7 \\
Level 4 & 183 & 10.5 \\
Level 5 & 1047 & 59.8 \\
\hline
\end{tabular}

Level 1 represents the lower level of food insecurity, while level 5 is the higher level of food insecurity

FAO and other authors [22, 43, 44]. The level of food insecurity in this region is higher than what was found in Kinshasa, the capital of DRC, and in other African countries [45-50]. The ongoing conflicts in North and South Kivu may be the key explanation to this as FAO has classified the Kivu region as high-conflict zone areas [22]. More than $70 \%$ of the study population resided in urban areas; unfortunately, the level of food insecurity measured in this study was worse compared to the results from studies done in other urban areas in Africa [43, 45, 46]. However, this study reinforced what other authors highlighted about the rapid increase in urban population due to rural migration, urban food crisis, and other related factors $[46,51-54]$. In the study region, many villages are deserted because of insecurity due to ongoing armed conflicts and wars. The unemployment rate, which increased with the growth of the urban population, could have worsened the situation. The surprisingly high prevalence of food insecurity in employed and self-employed people can be explained by the fact that employed people are mostly functionaries. They are underpaid and/or irregularly paid in Congolese francs, a highly unstable currency. Unfortunately, the variation in salaries does not follow the fluctuations of the currency, unlike goods on the market. The precarious socio-economic conditions in the region force employed and self-employed individuals to work hard to barely secure their livings while unemployed people can only rely on charity for their daily survival.

It was not surprising that regression also showed that wealth perception was statistically associated with household food insecurity level.

Unlike previous studies, the present results showed that men being the head of the household was not significantly associated with a lower likelihood of food insecurity $[8,9,11,35]$. However, Kassie et al. explained that the difference between male- and female-headed households is mainly because women often do not have the same access to remunerative work in Africa and they generally do not have a level of education that can help them cope [13]. Appleton and Duflo predicted that households headed by women would be less food insecure as women are responsible for preparing food for all of the family members. Contrary to men, women devote the bulk of their earnings to household expenditures which has positive effects on other members' welfare $[55,56]$. The assumption was not verified in the present study, probably because women-headed households would be more vulnerable to extreme poverty exacerbated by the long period of conflict in the region. 
Table 5 Multilevel ordinal regression of food insecurity (using the summative food insecurity scale based on FAO/ FIES scale 1-5, where 1 represents lower level of food insecurity and 5 represents higher level of food insecure)

\begin{tabular}{|c|c|c|c|c|}
\hline \multirow{2}{*}{$\begin{array}{l}\text { Variables } \\
\text { Age }\end{array}$} & \multirow{2}{*}{$\begin{array}{l}\begin{array}{l}\text { Odds } \\
\text { ratio }\end{array} \\
1.045\end{array}$} & \multicolumn{2}{|c|}{$\begin{array}{l}95 \% \\
\text { Confidence } \\
\text { interval }\end{array}$} & \multirow{2}{*}{$\begin{array}{r}\boldsymbol{p} \text {-value } \\
0.118\end{array}$} \\
\hline & & 0.988 & 1.105 & \\
\hline Age squared & 0.999 & 0.998 & 0.999 & 0.037 \\
\hline \multicolumn{5}{|l|}{ Education } \\
\hline No education (reference) & 1 & & & \\
\hline Primary & 0.764 & 0.519 & 1.126 & 0.174 \\
\hline Secondary & 0.594 & 0.403 & 0.877 & 0.009 \\
\hline University & 0.664 & 0.356 & 1.239 & 0.199 \\
\hline Number of children & 1.052 & 0.998 & 1.108 & 0.056 \\
\hline \multicolumn{5}{|l|}{ Wealth perception } \\
\hline Same (reference) & 1 & & & \\
\hline Much richer & 0.238 & 0.063 & 0.895 & 0.034 \\
\hline Somewhat richer & 0.351 & 0.239 & 0.518 & $<0.0001$ \\
\hline Somewhat poorer & 3.314 & 2.506 & 4.384 & $<0.0001$ \\
\hline Much poorer & 5.660 & 3.746 & 8.551 & $<0.0001$ \\
\hline Married & 1.611 & 0.927 & 2.800 & 0.090 \\
\hline \multicolumn{5}{|l|}{ Income-generating activities } \\
\hline None(reference) & 1 & & & \\
\hline Employment & 1.565 & 1.179 & 2.078 & 0.002 \\
\hline Self-employment & 2.266 & 1.484 & 3.452 & $<0.0001$ \\
\hline Urban (reference) & 1 & & & \\
\hline Rural & 0.483 & 0.326 & 0.714 & $<0.0001$ \\
\hline $\begin{array}{l}\text { Decision-making in the } \\
\text { couple }\end{array}$ & 0.687 & 0.538 & 0.877 & 0.003 \\
\hline \multicolumn{5}{|l|}{ Breadwinner } \\
\hline \multicolumn{5}{|l|}{ Myself (reference) } \\
\hline Husband/partner & 1.283 & 0.880 & 1.869 & 0.194 \\
\hline Someone else(relative) & 1.272 & 0.712 & 2.272 & 0.416 \\
\hline \multicolumn{5}{|l|}{ Relation to the head } \\
\hline Herself (reference) & 1 & & & \\
\hline Partner/husband & 0.633 & 0.399 & 1.004 & 0.052 \\
\hline Relative & 1.357 & 0.684 & 2.690 & 0.382 \\
\hline Violence scale & 1.296 & 1.054 & 1.594 & 0.014 \\
\hline Cut 1 & -1.656 & -0.422 & & -2.891 \\
\hline Cut 2 & -0.606 & -0.621 & & -1.833 \\
\hline Cut 3 & 0.086 & 1.314 & & -1.141 \\
\hline Cut 4 & 0.686 & 1.916 & & -0.542 \\
\hline Village var(cons) & 0.540 & 0.895 & & 0.326 \\
\hline
\end{tabular}

Significant results $(p<0.05)$ are presented in italic

Others found similar results that women-headed households faced multiple challenges, such as limited access to land ownership, technology, or lack of agriculture extension services [57]. However, women and men encounter the same agricultural technology challenges in the Kivu regions.

Tolerance of GBV was significantly associated with food insecurity, which corroborates other findings [5860]. However, previous studies also found that food insecurity increased gender-based violence and specifically intimate partner violence [61-64]. Fong et al. are among the few who stated that the relationship between genderbased violence and food insecurity could be bidirectional [61].

This study also found that an increased level of women's decision-making drivers downs the likelihood of food insecurity. Gendered divisions of labor generally place women in a central role in the preparation and production of food. Women's active participation in household decision-making, supported by higher levels of formal education, can challenge prevalent socio-cultural norms which unequally distribute food between genders [65, 66].

However, further research is needed to assess if women's participation in decision-making alone or tolerance of gender-based violence is associated with food insecurity, excluding potential mediators, such as societal norms.

\section{Strengths and limitations}

The strength of this study lies in being community based with a considerable participation rate. This study is among the few studies done to assess the food insecurity in North and South Kivu in DRC with special attention to gender and household power dynamics.

In the present study, food insecurity was an experienced scale measure of the household's ability to afford food. However, the scale did not consider other aspects that could have had a bearing on food insecurity, such as quality of food consumed, food fads, and food preference.

\section{Conclusion}

In regions with a high prevalence of food insecurity, measuring determinants of food insecurity is not easy. However, this study succeeded in contributing to the literature by highlighting several important findings. First, household wealth perception was strongly associated with food insecurity: the poorer the household, the more likely it was to be food insecure. A secondary level of education decreased the risk of food insecurity while having employment surprisingly increased the risk. Women's participation in decision-making was associated with lower levels of food insecurity. Finally, tolerance of violence was associated with higher levels of food insecurity.

More studies are needed to better understand the relationship between gendered aspects of household power dynamics and food insecurity. Cultural and 
societal barriers women face in the community may play an important role in the association between gender aspects and food insecurity. Further research could help better understand these associations and inform as of yet unexplored approaches to interventions to combat this prevalent regional challenge.

\section{Policy implications}

These results have policy implications for interventions aiming to fight food insecurity, especially in ongoing conflict zones. First, interventions should consider improving women's participation in household decision-making and reducing tolerance and experience of gender-based violence. This study suggests that interventions to improve food security must take into account gender dynamics in the household. For example, gender transformative approaches to empower women to express their opinions and sensitize men to reduce gender-based violence could have a positive impact on ensuring greater food security for more households. Further research on the effects of gender transformative approaches on food security outcomes would help develop more context-specific policies for implementation on local and regional levels.

\section{Abbreviations}

DHS: Demographic health survey; GBV: Gender-based violence; RDC: The Democratic Republic of the Congo; FAO: Food and agriculture organization; FIES: Food insecurity experience scale.

\section{Acknowledgements}

The authors acknowledge the community, local partners, and study participants for their willingness to contribute to this study. They thank Mari Dumbaugh who reviewed the manuscript critically for important intellectual content.

\section{Authors' contributions}

SM and WBA designed the study, coordinated research activities, and drafted the manuscript. GF coordinated data collection. GB was involved in drafting the manuscript. All the authors have read and approved the final manuscript.

\section{Funding}

The research activities were funded by the non-governmental organization CARE. Swiss TPH was subcontracted for monitoring, evaluation, and operations research of the Mawe Tatu program. The funder did not influence the study design, nor the data collection or analysis and interpretation of data.

\section{Availability of data and materials}

Dataset analyzed are not publicly available due to the confidentiality and anonymity of the study population. Datasets are stored on a secure Alfresco website and are available from the corresponding author on a reasonable request.

\section{Ethical approval and consent to participate}

The main research proposal was submitted and approved in 2016 by the EKNZ Ethical committee (Ethik Kommission Nord-und Zentralschweiz) in Switzerland and by the Ethics Committee of the Catholic University of Bukavu. This study is nested in an impact evaluation of the Mawe Tatu project in North and South Kivu, DRC. Informed verbal and written consent was obtained from all the participants of this study.
Consent of publication

Not applicable.

\section{Competing interests}

The authors declare that they have no competing interests.

\section{Author details}

${ }^{1}$ Swiss Tropical and Public Health Institute, Basel, Switzerland. ${ }^{2}$ University of Basel, Basel, Switzerland. ${ }^{3}$ Université Catholique de Bukavu, Ecole Régionale de Santé Publique de Bukavu, Bukavu, Democratic Republic of the Congo.

Received: 27 May 2020 Accepted: 1 January 2021

Published online: 28 April 2021

\section{References}

1. FAO, Unicaf, WFP and WHO. The State of Food Security and Nutrition in the World 2019. Safeguarding against economic slowdowns and downturs. Rome: FAO; 2019. p. 2019.

2. Frongillo EA. Validation of measures of food insecurity and hunger. J Nutri. 1999;129(2S Suppl):506S-S509.

3. FAO. World Food Summit-Final Report-Part 1. 19961996

4. Webb P, Coates J, Frongillo EA, Rogers BL, Swindale A, Bilinsky P. Measuring household food insecurity: why it's so important and yet so difficult to do. J Nutr. 2006;136(5):1404S-S1408.

5. Haile M. Weather patterns, food security and humanitarian response in sub-Saharan Africa. Philos Trans R Soc Lond B Biol Sci. 2005:360(1463):2169-82.

6. Maxwell D, Vaitla B, Coates J. How do indicators of household food insecurity measure up? An empirical comparison from Ethiopia. Food Policy. 2014;47:107-16.

7. Maxwell DG. Measuring food insecurity: the frequency and severity of "coping strategies." Food Policy. 1996;21(3):291-303.

8. Rukuni M. Africa: addressing growing threats to food security. J Nutr. 2002;132(11):3443S-S3448.

9. Abdullah S, Zhou D, Shah T, Ali S, Ahmad W, Din IU, et al. Factors affecting household food security in rural northern hinterland of Pakistan. I Saudi Soc Agric Sci. 2017;18:201-10.

10. Donn P, Ngondi JL, Tieguhong JC, Iponga DM, Tchingsabe O, Fungo R, et al. Poverty and poor education are key determinants of high household food insecurity among populations adjoining forest concessions in the Congo Basin. BMC Nutr. 2016;2(1):35.

11. Omonona, Bolarin T, Adetokunbo G. An analysis of food security situation among nigerian urban households: Evidence from Lago State, Nigeria. 2007:8(3):397-406

12. Tibesigwa B, Visser M. Assessing gender inequality in food security among small-holder farm households in urban and rural South Africa. World Dev. 2016;88:33-49.

13. Kassie M, Ndiritu SW, Stage J. What determines gender inequality in household food security in Kenya? Application of exogenous switching treatment regression. World Develop. 2014;56(C):153-71.

14. Handa S. Gender, headship and intrahousehold resource allocation World Dev. 1994;22(10):1535-47.

15. Quisumbing AR, Haddad L, Peña C. Are women overrepresented among the poor? An analysis of poverty in 10 developing countries. J Dev Econ. 2001;66(1):225-69.

16. Duflo E. Women empowerment and economic development. J Econ Literat. 2012;50(4):1051-79.

17. Ibnouf FO. Challenges and possibilities for achieving household food security in the Western Sudan region: the role of female farmers. Food Secur. 2011;3(2):215-31.

18. FAO, IFAD, UNICEF, WFP, WHO. The State of Food Security and Nutrition in the World 2017. 2017.

19. Watkins K, Quattri M. Child poverty, Inequality and Dêmography: why sub-saharian matters for Sustainable Development goals. 2016.

20. PNUD. A propos de la RDC 2013 (updated 2013).

21. Classification IIFSP. Democratic Republic of the Congo: acute food insecurity situation august 2018 | IPC global platform preliminary finding on pending the official release at country level 2018 (updated 2018). 
22. FAO. Food insecurity soars in conflict-ridden Democratic Republic of Congo - Democratic Republic of the Congo 2017 (updated 2017).

23. MPSMRM, MSP, International I. Enquête Démographique et de Santé en République Démocratique du Congo 2013-2014. Ministère du Plan et Suivi de la Mise en oeuvre de la Révolution de la Modernité (MPSMRM), Ministère de la Santé Publique (MSP) et ICF International. Rockville, Maryland, USA. 2014: 2014.

24. USAID. Food assistance fact sheet-democratic Republic of Congo | Food Assistance | U.S. Agency for International Development [facsheet]. 2018 (updated september 2018).

25. Elbert T, Hinkel H, Maedl A, Hermenau K, Hecker T, Schauer M, et al. Sexual and Gender-based violence in the Kivu Provinces of the Democratic Republic of Congo : insights from former Combatants.: World Bank; 2013. http://hdl.handle.net/10986/17852. Accessed 4 April 2019.

26. Johnson K, Scott J, Rughita B, Kisielewski M, Asher J, Ong R, et al. Association of sexual violence and human rights violations with physical and mental health in territories of the Eastern Democratic Republic of the Congo. JAMA. 2010;304(5):553-62.

27. Mukengere Mukwege D, Nangini C. Rape with extreme violence: the new pathology in South Kivu, Democratic Republic of Congo. PLoS Med. 2009;6(12):e1000204.

28. Nelson BD, Collins L, VanRooyen MJ, Joyce N, Mukwege D, Bartels S. Impact of sexual violence on children in the Eastern Democratic Republic of Congo. Med Conflict Surv. 2011;27(4):211-25.

29. Peterman A, Palermo T, Bredenkamp C. Estimates and determinants of sexual violence against women in the democratic Republic of Congo. Am J Public Health. 2011;101(6):1060-7.

30. Bapolisi W, Ferrari G, Blampain C, Bisimwa G, Merten S. Impact of a complex gender-transformative intervention on maternal and child health outcomes in the eastern Democratic Republic of Congo: protocol of a longitudinal parallel mixed-methods study. BMC Public Health. 2020;20(51):1

31. Rutsein SOaKJ. The DHS wealth index. DHS comparative reports Caverlton, Maryland, USA; 2004. Contract No.: 6.

32. Kendall A, Olson CM, Frongillo EA. Validation of the radimer/cornell measures of hunger and food insecurity. J Nutr. 1995;125(11):2793-801.

33. Radimer KL, Olson CM, Greene JC, Campbell CC, Habicht J-P. Understanding hunger and developing indicators to assess it in women and children. J Nutr Educat. 1992;24(1, Supplement 1):36S-44S.

34. Lokosang LB, Ramroop S, Hendricks LS. Establishing a robust technique for monitoring and early warning of food insecurity in post-conflict South Sudan using ordinal logistic regression. Agrekon. 2011;50(4):101-30.

35. Asesefa Kisi M, Tamiru D, Teshome MS, Tamiru M, Feyissa GT. Household food insecurity and coping strategies among pensioners in Jimma Town, South West Ethiopia. BMC Public Health. 2018;18(1):1373.

36. Swiss Tropical and Public Health Institute. Adolescent and youth sexual and reproductive health survey: survey report 2014 South Kivu province, DRC. 20152015.

37. Gari S, Malungo J, Matin-Hilber A, Schlinder C, Merten S. HIV testing and tolerance to gender based violence: a cross-sectional study in Zambia. PLOS ONE. 2013;8(8):71922.

38. Stochl J, Jones PB, Croudace TJ. Mokken scale analysis of mental health and well-being questionnaire item responses: a non-parametric IRT method in empirical research for applied health researchers. BMC Med Res Methodol. 2012;12:74.

39. Loevinger J. The technic of homogeneous tests compared with some aspects of scale analysis and factor analysis. Psychol Bull. 1948;45(6):507-29.

40. Sijtsma K, Molenaar IW. Reliability of test scores in nonparametric item response theory. Psychometrika. 1987;52(1):79-97.

41. Brenton P, Bashinge C, Hossein C, Nagaki S, Ntagoma J-B. Risky Business: Poor women cross-border traders in the great Lakes Region of Africa. Africa trade policy; 2011.

42. Nfundiko JS. Femmes du Sud-Kivu, victimes et actrices en situation de conflit et postconflit. Herodote. 2015;158(3):182-99.

43. Alinovi L, Hemrich G, Russo L, Alinovi L, Hemrich G. addressing food insecurity in fragile states: case studies of democratic republic of Congo, somalia and sudan: ESA Working Papers 2007.

44. Kaluski DN, Ophir E, Amede T. Food security and nutrition-the Ethiopian case for action. Public Health Nutr. 2002;5(3):373-81.
45. Battersby J, Watson V. Addressing food security in African cities. Nat Sustainabil. 2018;1(4):153-5.

46. Birhane T, Shiferaw S, Hagos S, Mohindra KS. Urban food insecurity in the context of high food prices: a community based cross sectional study in Addis Ababa. Ethiopia BMC Pub Health. 2014;14:680.

47. Crush J, Frayne B, Pendleton W. The crisis of food insecurity in African cities. J Hunger Environ Nutr. 2012;7(2-3):271-92.

48. Hadley C, Linzer DA, Belachew T, Mariam AG, Tessema F, Lindstrom D. Household capacities, vulnerabilities and food insecurity: Shifts in food insecurity in urban and rural Ethiopia during the 2008 food crisis. Soc Sci Med. 2011;73(10):1534-42.

49. Lebailly P, Muteba D. Characteristics of Urban food insecurity: the case of Kinshasa. Afr Rev Econ Finan. 2011;3(1):58-68.

50. Verpoorten M, Arora A, Stoop N, Swinnen J. Self-reported food insecurity in Africa during the food price crisis. Food Policy. 2013;39:51-63.

51. Chinnakali P, Upadhyay RP, Shokeen D, Singh K, Kaur M, Singh AK, et al. Prevalence of household-level food insecurity and its determinants in an urban resettlement colony in North India. J Health Popul Nutr. 2014;32(2):227-36.

52. Craveiro I, Alves D, Amado M, Santos Z, Fortes AT, Delgado AP, et al. Determinants, health problems, and food insecurity in urban areas of the largest city in cape verde. Int J Environ Res Public Health. 2016;13(11):1155.

53. Omba JK. Socioeconomic impact of armed conflict on the health of women and children in the Democratic Republic of the Congo. Medecine Tropicale Revue du Corps de sante colonial. 2011;71(2):192-6.

54. Tacoli C. Food (In)security in rapidly Urbanising, low-income contexts. Int J Environ Res Public Health. 2017;14(12):1554.

55. Appleton S. Women-headed households and household welfare: an empirical deconstruction for Uganda. World Dev. 1996;24(12):1811-27.

56. Duflo E, editor Policy paper bureau for research in economic analysis of development gender equality in development. 2005.

57. Negesse A, Jara D, Habtamu T, Dessie G, Getaneh T, Mulugeta H, et al. The impact of being of the female gender for household head on the prevalence of food insecurity in Ethiopia: a systematic-review and metaanalysis. Public Health Rev. 2020;41(1):15.

58. Diamond-Smith N, Conroy AA, Tsai AC, Nekkanti M, Weiser SD. Food insecurity and intimate partner violence among married women in Nepal. J Glob Health. 2019;9(1):010412.

59. Ricks JL, Cochran SD, Arah OA, Williams JK, Seeman TE. Food insecurity and intimate partner violence against women: results from the California Women's Health Survey. Public Health Nutr. 2016;19(5):914-23.

60. Whittle HJ, Palar K, Hufstedler LL, Seligman HK, Frongillo EA, Weiser SD. Food insecurity, chronic illness, and gentrification in the San Francisco Bay area: an example of structural violence in United States public policy. Soc Sci Med. 2015;143:154-61.

61. Fong S, Gupta J, Kpebo D, Falb K. Food insecurity associated with intimate partner violence among women in Abidjan. Cote d'Ivoire Int J Gynaecol Obstet. 2016;134(3):341-2.

62. Hatcher AM, Stockl H, McBride RS, Khumalo M, Christofides N. Pathways from food insecurity to intimate partner violence perpetration among Peri-Urban men in South Africa. Am J Prev Med. 2019;56(5):765-72.

63. Lim S, Park JN, Kerrigan DL, Sherman SG. Severe Food Insecurity, genderbased violence, homelessness, and HIV risk among street-based female sex workers in Baltimore. Maryland AIDS Behav. 2019;23:3058-63.

64. Miller CL, Bangsberg DR, Tuller DM, Senkungu J, Kawuma A, Frongillo EA, et al. Food insecurity and sexual risk in an HIV endemic community in Uganda. AIDS Behav. 2011;15(7):1512-9.

65. Hyder AA, Maman S, Nyoni JE, Khasiani SA, Teoh N, Premji Z, Sohani S. The pervasive triad of food security, gender inequity and women's health: exploratory research from Sub-Saharan Africa. Afr Health Sci. 2005;5(4):328-34.

66. Rao N. Land rights, gender equality and household food security: exploring the conceptual links in the case of India. Elsev Food Policy. 2006;31(2):180-93.

\section{Publisher's Note}

Springer Nature remains neutral with regard to jurisdictional claims in published maps and institutional affiliations. 